\title{
"Vida y muerte de la Mulata". Crónica ilustrada de la prostitución en la Cuba del XIX
}

\author{
Juan Andreo García \\ Universidad de Murcia \\ Alberto José Gullón Abao \\ Universidad de Cádiz \\ “...las mulatas, ;ah!, las mulatas... de ellas es la calle” \\ Condesa de Merlín
}

\begin{abstract}
El presente artículo pretende una aproximación a un tema un tanto olvidado por la historiografía cubana: el de la prostitución en la segunda mitad del siglo XIX, tema que presenta graves problemas; entre ellos destaca la falta de fuentes directas ya que el Gobierno Civil destruyó tras la guerra hispano-cubana los antecedentes que había en sus archivos de la sección de Higiene. Por eso proponemos la utilización de fuentes menos convencionales (la litografía) que pueden ser tanto o más reveladoras que las tradicionales. Concretamente nos referimos a las ilustraciones que envolvían las cajetillas de tabaco cubano -las marquillas - que constituyen por sí mismas una verdadera joya artística, además de un reflejo, de la realidad social y económica del entorno en el que se crearon. Estas marquillas se agrupan en series coleccionables de las que el objeto de nuestro estudio serán las que se recogen con el título "Vida o Vida y muerte de la Mulata".
\end{abstract}

\section{Introducción}

Uno de los graves problemas para estudiar la prostitución en la segunda mitad del siglo XIX ha sido la falta de fuentes seriadas ya que, al parecer, el Gobierno Civil destruyó tras la guerra hispano-cubana los antecedentes que había en sus archivos de la sección de Higiene. Asimismo, hay un hueco historiográfico considerable por tratarse de una cuestión que, durante muchos años se ha considerado tabú y de escaso interés para la historiografía, incluidos los investigadores de la historia social.

La documentación con la que hemos venido trabajando básicamente para el análisis de este asunto han sido informes médicos de la época centrados, en su mayoría, en la ciudad de La Habana y que conllevan juicios o prejuicios de valores propios del momento, que podrían llevar al investigador a equívocos, distorsionando o tamizando la realidad. 
Por ello hemos creido necesaria la utilización de fuentes menos convencionales, como la tradición oral, el folclore, la prensa, el grabado o la litografía, etc., que puedan ser tanto o más reveladoras que las tradicionales (de archivo y bibliográficas), de cara al mejor conocimiento de un fenómeno que, aunque sabido a grandes rasgos, adolece de matices importantes para la total comprensión y alcance en una sociedad que se vio seriamente afectada por él. En consecuencia, pretendemos una modesta aproximación a un tema un tanto olvidado por la historiografía cubana que, a nuestro juicio, es de vital importancia para tratar de entender una historia social mas globalizadora y adentrarse en el mundo de fines del XIX cubano desde una perspectiva diferente a la estudiada hasta ahora.

Por otro lado, el presente trabajo constituye el resultado de la aceptación de dos premisas que los autores, hace algún tiempo y por distintos caminos, hemos hecho nuestras. Es este un intento de reflexión y de respuesta, primero a lo que creemos es un reto y segundo, a lo que opinamos es una consideración metodológica; la procedencia de las dos se ubica en las orillas opuestas del Atlántico - Cuba y España — lanzadas ambas por dos excelentes maestros de historiadores, Fernando Ortiz y después el profesor Fontana.

Las dos propuestas giran en torno a lo que consideramos fuentes básicas para los nuevos enfoques de la historiografía actual: las artes gráficas. En el primer caso, tomamos la propuesta de Fernando Ortiz como un verdadero reto; ya hacia 1963 el citado autor, hablando del tabaco, decía: "sobre todo los cigarros y cigarrillos en las cajetillas con sus innumerables diseños y contraseñas dieron origen a una rica producción litográfica... el caudal ingenioso de los dibujos de las cajetillas, cubrió todos los campos, desde la geografía a la realeza y al ejército, hasta la ironía y la picaresca pornográfica... ¡Nadie lo ha estudiado todavía!. Pocos libros conservan muestras de esas grafías tan ricas y originales del pueblo de Cuba. ¿Quien las estudiará?". ${ }^{1}$ El segundo caso es una consideración metodológica no menos incitadora que la primera. El profesor Fontana, a la hora de hablar de la importancia de las fuentes orales, dice: "al historiador le importa tanto conocer los hechos como las representaciones que de tales hechos se formaban los hombres que los vivieron. Acertadas o erróneas, fueron estas, en última instancia, las que determinaron su actuación". Y lo mismo podría aplicarse a las fuentes gráficas. ${ }^{2}$

1 Ortiz, Fernando: Contrapunteo cubano del tabaco y el azúcar. La Habana, 1963.

2 Fontana, J.: "La crisis colonial en la crisis del Antiguo Régimen", en Bonilla, Heraclio (Ed.): El sistema colonial en la América Española. Barcelona, 1991, pág. 305. 
Como se puede apreciar, estamos reivindicando el estatuto de fuente histórica para las litografías, y concretamente para las que envolvían las cajetillas de tabaco cubano - las marquillas - que constituyen por sí mismas una verdadera joya artística, y -atendiendo a su contenido gráficoademás un reflejo, una fotografía de la realidad social y económica del entorno en el que se crearon y donde vivieron las manos y las mentes que las hicieron. No cabe duda que en la litografía, en el grabado, importa todo para el análisis: la composición (los personajes en sus actitudes, su vestimenta y los objetos que les rodean), el paisaje con su estructura y materialidad y, por supuesto, lo que el autor quiere transmitir a la posteridad.

Importa mucho reiterar que esto es sólo un intento de aproximación a lo que consideramos una ingente tarea investigadora. A la marquilla, no puede negarse, se le ha otorgado una cierta autoría y presencia en los estudios sobre el tabaco o en la historia del arte cubano; pero nosotros queremos ir más allá, al propugnar su utilidad para otros análisis distintos. Recordemos las palabras de Bernardo Riego: "Ningún historiador puede soslayar hoy en día el carácter de huella que la imagen grabada o la litografía tienen". ${ }^{3}$ Es evidente que, para que esas imágenes cumplan con el estatuto de la investigación histórica, son necesarias una profunda revisión y puesta al día metodológica que las dote de verdadera entidad; pero estas imágenes tienen un discurso vital que debe ser abordado desde una metodología de estudio específica que el historiador tiene que encontrar, pues no cabe duda de que se constituyen y tienen el estatuto de fuente para el conocimiento histórico, según la genérica y ya clásica definición que diera el profesor Topolsky. ${ }^{4}$

\section{Un intento de contextualización: La prostitución en Cuba durante el siglo XIX}

\section{La prostitución y su reglamentación}

La prostitución, por muchos y diferentes motivos, según las coyunturas históricas, se mantuvo en Cuba largo tiempo como un rentable negocio para muchos amos de esclavas y se promovió desde muy temprano en la isla.

3 Riego, Bernardo: "La fotografía como fuente de la Historia Contemporánea: Las dificultades de una evidencia”, en: La imatge i la recerca histórica, noviembre, 1990, pág, 197. Las palabras en cursiva son nuestras, el autor habla de la imagen fotográfica.

4 Topolsky, Jerzy: Metodología de la Historia. Madrid, 1982, pág. 300. "El concepto de fuente histórica abarca todas las fuentes del conocimiento histórico, (directas o indirectas) es decir, toda la información sobre el pasado humano, donde quiera que se encuentre, junto a los modos de transmitir esa información (canales de información)". 
A mediados del siglo XIX se establecerán en España los primeros reglamentos que pretenderán organizar bajo vigilancia municipal los burdeles oficiales, locales registrados con un control sanitario. ${ }^{5}$ Las distintas enfermedades venéreas: sífilis, gonorrea, etc... generaron auténticos estragos entre los varones comprendidos en edades productivas, tanto desde el punto de vista económico como reproductivo. ${ }^{6}$ En el caso concreto de Cuba, esta situación sanitaria se agravó con el continuo número de conflictos armados entre los ejércitos españoles e independentistas en la segunda mitad del XIX. Este problema cobró mayor relevancia en las ciudades, que se caracterizaron siempre por una abrumadora mayoría de población masculina. A ello coadyuvó la situación de la isla y el papel dado a ésta por la Corona española. El movimiento continuo de inmigrantes, soldados y marineros, propio de toda ciudad portuaria - sobre todo en una ciudad de tan alto volumen comercial e importancia como La Habana- originó indefectiblemente una ingente presencia de hombres en estado de soltería y la consiguiente demanda de sexo femenino. Todo ello confirma la opinión de Moreno Fraginals de que este negocio de la prostitución de negras y mulatas esclavas y también libres, llegó a sus más altas cotas hacia la mitad del siglo XIX, cuando hubo que agrupar a las gentes de ese oficio en tres, luego en cuatro y hacia 1888 en cinco demarcaciones de la ciudad de La Habana. ${ }^{7}$

Tenemos noticias de que en un principio muchas casas de prostitución servían de casas de juego y salón de bailes. A mediados del siglo XIX existían zonas concretas de prostitución, aunque no tenemos la certeza de si estaban localizadas en un barrio específico. ${ }^{8}$ En 1865 , el gobernador político pone de manifiesto las órdenes vigentes a este respecto en ese momento: que no se abran casas públicas a no ser en los puntos designados y que no se traspasen los existentes. ${ }^{9}$

5 Vázquez García, Francisco; Morales Mengíbar, Andrés: "Política de burdel en la España Comtemporánea. De las propuestas Ilustradas a la prostitución reglamentada”. Cuadernos de la Ilustración al Romanticismo, n. ${ }^{\circ}$ 1. Cádiz 1991, págs. 55-77.

6 Capel Martínez, Rosa María: "La prostitución en España. Notas para un estudio socio-histórico”, en Mujer y sociedad en España. 1700-1975. Madrid, 1986, págs. 265-298.

7 Moreno Fraginals, Manuel: Cuba / España. España / Cuba. Historia Común. Barcelona, 1995, pág. 178.

8 Biblioteca Nacional de Madrid, Manuscrito 20138 (en adelante BN, Mss.). La Habana, 24 de noviembre de 1867. El gobernador político al comisario del tercer distrito, sobre el traslado de las meretrices a los puntos señalados en la disposición del 31 de marzo de 1853.

9 Ibídem. La Habana, 1 de septiembre de 1865. Oficio del gobernador político sobre la solicitud de los vecinos de la Calle Compostela. 
En 1873, se puede decir que no existe un único barrio, es más, diremos que toda La Habana Vieja es un gran centro de prostitución. Para intentar paliar de algún modo esta situación, se establece una normativa que regule las casas toleradas y su estructura física. Así el artículo 20 del Reglamento de 1873 estipula que las amas y prostitutas habitarán los pisos altos. ${ }^{10}$ Como es de suponer estas normativas tienen poca repercusión y en los siguientes reglamentos se intenta perfeccionarlas.

Ese mismo año - 1873- el gobernador político Pérez de la Riva, ordena que en vista del crecido número de prostitutas existentes en la ciudad "por las naturales causas de la guerra", se inscriban con objeto de allegar una cuota para cubrir los gastos originados por la creación de una plaza de médico higienista y una sección especial administrativa. En junio se abrió, en el que fuera hospital de niños pobres de San José, el denominado "Hospital de Higiene" y se dictó el llamado Reglamento especial de Higiene Pública. ${ }^{11}$

Los objetivos generales de la Sección Especial de Higiene Pública eran prevenir y evitar los malos efectos de la prostitución, disminuyendo ésta en lo posible, para que no se molestase a la "moral pública". Esta sección dependería de la Secretaría del Gobierno Político y sus funciones eran llevar un registro de las prostitutas y recaudar impuestos que se les cobrarían para su cuidado y atención médica; asimismo, los libros de entradas y salidas de las enfermas del hospital de San Francisco de Paula y el registro de las multas.

Por supuesto, los reglamentos contenían muchos más puntos que la mera supervisión sanitaria. Para la "autoridad" era necesario un cierto control del tiempo de revisión y una reglamentación de movimientos de las prostitutas, su localización; así, buena parte del interés radicaba en dirigir la prostitución dentro de lo que se denominaba un cierto "orden moral", que permitiese regular los usos y costumbres de estas mujeres hasta en los más mínimos detalles, para que fueran fácilmente identificables y no confundirlas con las "honradas".

Pero el incremento de enfermos venéreos en determinados períodos, la falta de prostitutas registradas en el hospital y los sucesivos reglamentos - como los formados por el doctor Claudio Delgado o el mandado elabo-

\footnotetext{
10 Reglamento especial de Higiene Pública. La Habana, 27 de diciembre de 1873.

11 Gullón Abao, Alberto J.: "Un acercamiento a la prostitución cubana de fines del Siglo XIX". Comunicación presentada al Congreso internacional La nación soñada: Cuba, Puerto Rico y Filipinas ante el 98. Aranjuez, 1996, págs. 497-507.
} 
rar por el gobernador civil Francisco Cassa- ponen de manifiesto los graves problemas que suscitaba el sistema, aunque se consiguiera una cierta eficacia.

A ello hay que unir que no todas las prostitutas estaban regladas; existían las que ejercían el oficio sin ningún control o ilegales. Estas últimas indiscutiblemente eran mucho más numerosas que las que se ajustaban a ley. Las razones hemos de buscarlas entre otras causas en motivos económicos, considerandos médicos, etc., impedimentos que, de alguna manera, influían para que no se registrasen en los libros. Las fuentes para el estudio de las ilegales son difíciles de detectar y escasas, y la poca información que hemos obtenido hasta ahora es indirecta, a través de algún que otro pleito o informadores de la época.

\section{Burdeles y prostitutas}

En el censo de burdeles y prostitutas, según el color, hecho en La Habana en 1869 , encontramos un total de 498 prostitutas. ${ }^{12}$ De ellas, pardas eran 19 y negras 27 , lo que supone un $9 \%$ del total, cifra realmente reducida. Otros datos nos informan que en 1874 y 1875 existían unas 400 prostitutas inscritas y en 1878, 500; el número oscilará entre 450 y 500 hasta 1886.

Un observador de la época informa que la prostitución pública estaba constituida por una clase de mujeres blancas inmigrantes, arrojadas aquí como desechos de los puertos de Costa Firme, Repúblicas americanas y Canarias; y mujeres de color acomodadas por los amos que posteriormente vinieron a menos ${ }^{13}$ salvaguardando el autor, la pureza de las cubanas blancas. Claro que si se analiza su procedencia geográfica tomando como referencia las meretrices que fueron asistidas en el Hospital de la Higiene en varios años, se puede matizar lo anterior.

Como era de esperar, el grupo más numeroso lo formaban las cubanas con el 53\% aproximadamente del total, aunque se percibe un claro incremento para el año 1887 hasta alcanzar la cifra del 65,6\%. Si trabajamos tan sólo con las cubanas blancas los datos varían sustancialmente, ya que éstas suponen entre el 19 y $22 \%$ - exceptuando el primer año en el que se registra un $26 \%$ - lo que indica un fuerte incremento en las prostitutas regladas registradas como de color.

12 Stolcke, Verena: Racismo y sexualidad en la Cuba Colonial. Madrid, 1992, pág. 18.

13 Céspedes, Benjamín de: La prostitución en la Ciudad de La Habana. La Habana, 1888. 
CRÓNICA ILUSTRADA DE LA PROSTITUCIÓN EN LA CUBA DEL XIX

MERETRICES ASISTIDAS EN EL HOSPITAL DE LA HIGIENE

\begin{tabular}{lrrrr} 
& 1873 & 1874 & 1875 & 1887 \\
\hline Blancas & 96 & 196 & 169 & 212 \\
Color & 30 & 92 & 98 & 161 \\
\hline TOTAL & 126 & 288 & 267 & 373
\end{tabular}

Si estudiamos los porcentajes entre las prostitutas de color y las blancas observamos que, al menos dentro del submundo que supone la prostitución reglada, son las blancas las que tienen mayor porcentaje, aunque con un claro declive que va desde el $76,1 \%$ en 1873 hasta el $56,8 \%$ en 1887. Esto se podría explicar por la relativa facilidad con que muchos jóvenes blancos de la Isla se iniciaban sexualmente con las mujeres del servicio doméstico, generalmente pardas, mulatas o negras, lo que hacía difícil que se pagara para "disfrutar de ellas". Pero la presencia de hombres blancos venidos de España, que suponemos veían algo exótico en las negras y mulatas, debió aumentar la demanda de las meretrices de color. Además, podríamos afirmar que la gran mayoría de ilegales eran de color (mulatas) y las autoridades vigilaban más a las blancas por una cuestión de un cierto "orden moral", herencia sin duda del régimen esclavista. Ahora bien, datos obtenidos de 1899, nos informan que de 214 clandestinas atendidas en los servicios sanitarios, el 42,5\% eran blancas, mientras que las "mestizas" suponían el 28,7\% y las negras el $28,5 \% .^{14}$ Estos datos podrían hacer dudar de la afirmación que anteriormente hacíamos sobre que la mayoría de las ilegales eran de color (entendiendo esto como legalmente de color, que no por la tintura de la piel), aunque sospechamos que lo cierto es que existía un mayor control de las blancas por razones de "moralidad y orden social"; ${ }^{15}$ mientras que pardas y mulatas ejercían su trabajo de manera encubierta, fuera del control en la mayoría de los casos de amas o alcahuetas, y posiblemente a título particular, una vez que habían fracasado sus intentos de "blanquearse" casándose o amancebándose con algún criollo o penínsular blanco. En torno a la vida y profesión de estas mujeres de color establecemos el objeto del presente estudio.

14 Alfonso, Ramón María: La prostitución en Cuba. La Habana, 1905.

15 Ibídem. 


\section{Las "marquillas" tabaqueras y la imagen popularizada de un determinismo social}

\section{Las marquillas}

En una reciente visita a la Biblioteca Nacional José Martí en La Habana, pudimos comprobar la existencia de miles de estas marquillas de las que una gran parte al menos, están encuadernadas, como después constatamos en tres voluminosos cuadernos titulados "Álbum de cromos" ${ }^{16} \mathrm{Ya}$ existe, al menos, publicado un precioso catálogo, ${ }^{17}$ que viene a ser una primera aproximación a un inventario y una sistematización de estas joyas litográficas contextualizadas en la historia cubana del XIX muy unidas, como es claro, al tabaco. Hay autores que ya han hecho referencia a estas "pequeñas obras de arte", aunque haya sido sólo poniendo hincapié en el interés documental de esas "tiras dibujadas" que suponen "una riqueza incalculable como documentación. Ligeras, agudas y eminentemente populares, estas estampas constituyen un legado cuya importancia sobrepasa su intrínseco valor pictórico". ${ }^{18}$ En definitiva, es lo que nosotros, líneas arriba, hemos afirmado como excelente valor de cara al análisis histórico de la sociedad que generó dichas estampas.

Estas marquillas describen una enorme variedad de temas. Su estructura básica consiste en una escena central con un pie de comentario rodeada por una serie de alegorías referentes - en la mayoría de los casos- al motivo central de la serie o al nombre y excelencias de la fábrica de tabaco que las manda imprimir.

No es momento de analizar los diferentes temas de que tratan estas series. Baste decir que van desde los "almanaques del año 1866" hasta "historia santa"; desde "galerías de soberanos" hasta los "uniformes de los voluntarios españoles en Cuba"; desde colecciones culturales como "alfabeto zoológico" al "ornitológico"; desde los paisajes de Europa a los de Cuba; desde la seriedad de los personajes de la "corte del Papa" a la socarronería, crítica mordaz y excelentes caricaturas de "cosas de La Ha-

16 Catalogadas y encuadernadas en esos tres volúmenes existen 3.932 marquillas.

17 Núñez Jiménez, Antonio: Cuba en las Marquillas cigarreras del S. XIX. La Habana, 1985. Las reproducciones las hemos entresacado de este catálogo, por su perfecta calidad y accesibilidad, así como por no perjudicar, en lo posible, los originales. Agradecemos al personal y a las jefas de sección de raros y manuscritos de la mencionada Biblioteca las facilidades prestadas, así como su simpatía y disponibilidad.

18 Juan, Adelaida de: Pintura y grabados coloniales. La Habana, 1974. 
bana". Atendiendo a los criterios de mordacidad e ingenio de los autores de las viñetas, destacan por sí mismas las frases que se situan al pie de las escenas.

En cuanto a las fabricas más afamadas en este tipo de adorno para sus mercancías, sobresalen: "La Honradez", que reza en subtítulo: "Los hechos me justificarán", certificando a continuación que son proveedores de la Casa Real de España y de los Reyes de Portugal, y transcribiendo después su dirección comercial: Calle Cuba, núms. 83 y 85, y menudeo, Calle del Obispo, n. ${ }^{\circ}$ 15. "La Real fabrica de Eduardo Guilló", que en los adornos alegóricos explica sus premios y que es proveedora de S.M. Su dirección en Calle de los Oficios, n. ${ }^{\circ} 23$, y "La Charanga de Villegas" subtitulada "de lo bueno lo mejor", Llaguno y compañía, Calle O’Reilly, n. ${ }^{\circ} 9^{1 / 2}$.

\section{El destino de la mulata o la plasmación gráfica de un mito}

En las historias que vamos a describir, no aparece de forma evidente el oficio que venimos describiendo; es claro que a esas alturas del siglo no se podía hablar de tamaño problema sin más. Una sociedad como la cubana respiraba aún suficiente grado de tradicionalismo religioso y de conservadurismo moral, que sabía aplicar perfectamente a la salvaguarda de las formas.

Ante esa "imperceptible represión", las manifestaciones populares buscan transgredir la vigilancia y con una interesante picardía e ingenio, saben plasmar una serie de mensajes "aparentemente ocultos" pero, en realidad muy claros para la sociedad a la que van dirigidos. En consecuencia, "la mulata" que nos aparece no es la prostituta convencional que conocemos, aunque lo que le rodea (los personajes), sus ademanes, sus gestos y actividades están claramente definidos y catalogados como los de aquella mujer que trafica con su sexo.

Todas las fabricas de tabaco dedicaron algunas de sus colecciones a narrar la historia entre moralizante, crítica e irónica, de la vida, destino y fin de la mulata. Casi todas las series tienen la misma estructura, aunque cambia lógicamente su textura según el autor y las alegorías que enmarcan la viñeta central y sobre todo el título general de la historieta. Citando las tres casas comerciales de las que hemos hablado, podemos describir algunas características de cada serie. "La Charanga de Villegas" —quizás la más completa - reúne una serie de 15 viñetas numeradas, rodeadas de 
una recargada cenefa de alegorías de personajes (músicos) que hacen referencia al nombre comercial. La historia recibe el título de Vida y muerte de la Mulata.

La primera viñeta, representa a la puerta de una cantina un comerciante sentado y fumando apaciblemente, quizá vigilando su negocio, o bien al pie de la barra mostrador en donde es posible esté tomando alguna bebida; el mencionado personaje alarga su brazo y da dinero a una mujer de color. El pie de la ilustración reza así: El que siembra coje. No cabe duda que, de forma aislada, la imagen puede ser un tanto ambigua, pero si vemos toda la secuencia, y sobre todo la segunda viñeta, la referencia es clara: el personaje masculino está ganándose, o pagando, los favores, inequívocamente sexuales, de la mujer negra.

En el segundo cromo, aparece el mismo señor, ya vestido con ropa de paseo y bastante elegante - lo cual denota el status social del mismo (comerciante) - en la casa de la mujer negra que, con los pechos al aire, muestra un evidente embarazo, al que hace referencia el pie de texto: No es muy grata la cosecha.

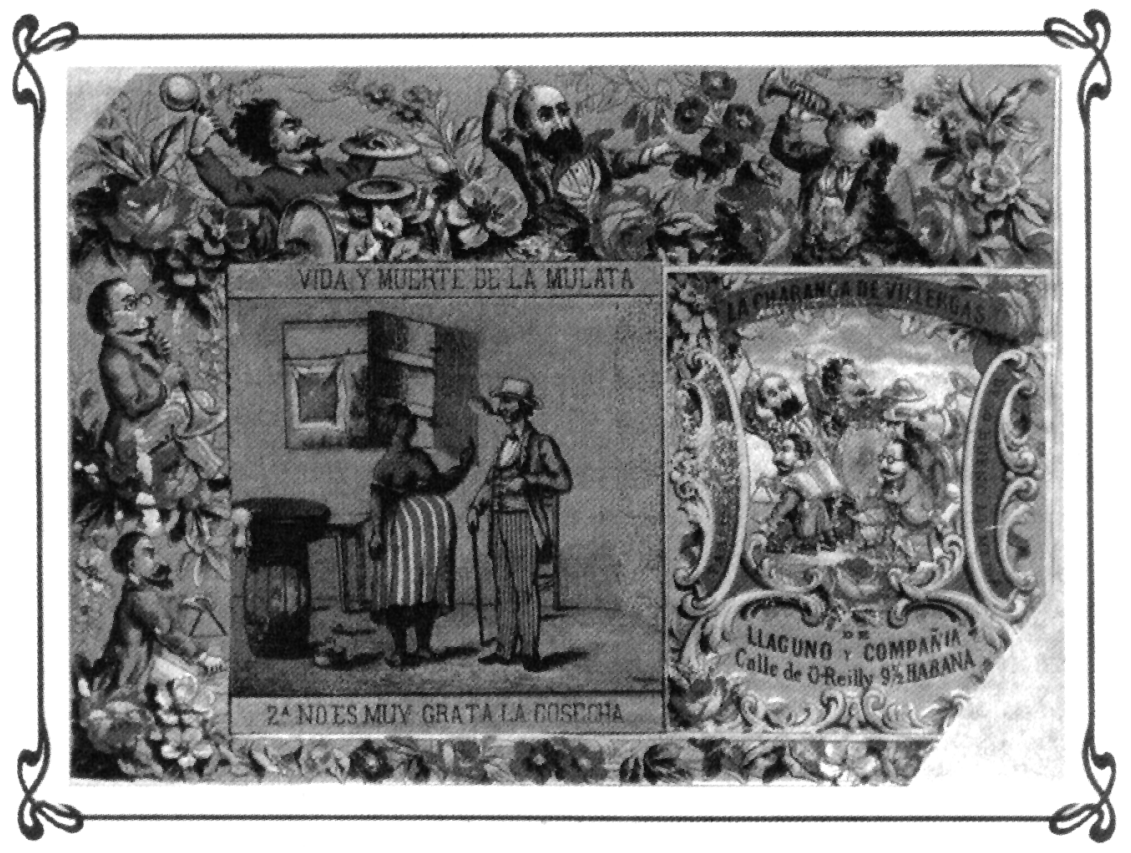


En la tercera viñeta, aparece la mujer de color con un bebé en brazos y una mulatica de la mano, pasando por delante de la taberna (negocio) del mismo señor, que está en el quicio de la puerta, presenciando cómo la niña se dirige a un chaval que la mira, no sabemos si incitándole a jugar o ya con la malicia insinuadora que ha aprendido en la casa materna, pues el texto reza: Promete óptimos frutos.

En las siguientes viñetas se narran las actividades de la mulatica, ya mujer exuberante, vestida de forma "provocativa" y con modales y actitudes del mismo tono. Pero es interesante un cierto matiz de ilusión de la mujer, que cree en las buenas intenciones del caballero que la va a sacar de su status social, soñando que se cumpla ese deseo; pues en cuarta viñeta de la serie, el amante dice: Si me amas serás feliz. La mulata, ilusionada por esa esperanza, en la viñeta siguiente huye de su choza y del ambiente en el que había nacido: Una retirada a tiempo.

Ya en una casa más lujosa mirándose al espejo, vestida con un ceñido corsé, se autoconvence: Mi querido dice tenga esperanza. En las siguientes imágenes la mulatica se regodea y se convence de su belleza que le sirve para que los hombres la sigan, la rodeen de atenciones en el baile, en las fiestas, etc. No obstante, ya en la viñeta número once, las cosas empiezan a cambiar: Vientos de proa, la belleza se marchita y vemos a la mulatica en la calle con una botella en la mano y, desgreñada, acaparando la atención de un hombre, pero ahora ese hombre es de color y su profesión es de cochero: ¿Caridad quieres mecha?... ¡iSiaa!!. En la siguiente es llevada presa por un guardia civil: El castigo. Con el texto de Las consecuencias, aparece en la viñeta número catorce la imagen de una sala de hospital llena de camas con mulatas enfermas, y por último en la número quince, una carreta funeraria de color negro y el inequívoco texto: Fin de todo placer. Imagen que cobra un marcado carácter por su contraste con la de una mujer blanca que cruza la calle, parece que viniendo de oír misa, pues lleva un velo puesto.

Otra de las series sobre el tema recibe el nombre de Historia de la Mulata, de la casa "Real fabrica de Eduardo Guilló". Esta historieta sigue casi idéntica estructura que la anterior; pero en ella destaca una viñeta central de mayor tamaño y más clara en su textura gráfica, en la que se aprecia más nítidamente el entorno que rodea a los personajes. En la serie se ve, primero, a unos caballeros que delante de una bodega - la del Gabilánadornada con todo detalle, regalan y cortejan a una joven negra. Al pie se lee: Escuela de primeras letras. En la siguiente un marinero compra a una 
negra uno de los frutos que ésta lleva en una tabla sobre la cabeza: Poner los medios para conseguir los fines. Viñeta, como la de la serie anterior, inocente en su apariencia, si no fuera por la que le sigue, en la que la misma negra aparece delante de un comercio visiblemente embarazada: Percances del oficio. En otra estampa la negra, con la mulata de la mano, exige al marinero, en la puerta de su choza frente a la bahía, dinero, parece que para mantener a la hijita de ambos: Ataque directo al bolsillo; como queriendo ejemplificar que aquella relación tiene consecuencias un tanto incómodas para el bolsillo del marino. Enseguida, la mulata aparece siendo regalada y mantenida por un caballero en una suntuosa casa: El palomo y la gabilana. En la siguiente ese "palomo" (chulo), recoge el dinero que un burgués acomodado le da a la mulatica. Finalmente, viñetas después, esa mulata rodeada de miseria, lava la ropa rodeada de cuatro hijos: Algunos polvos traen estos lodos. Finaliza la serie con la inequívoca tétrica imagen de la muerte.

Otro tanto ocurre en la serie La vida de la Mulata, de la Fabrica "La Honradez". Tiene esta serie unos colores más oscuros y fuertes y un marcado carácter caricaturesco en sus personajes. En ella se narra la vida de la mulata desde su nacimiento de una negra criada y un padre blanco, pasando por la vida alegre y regalada por piropos de los caballeros en el paseo: Dios te guarde, sabrosona; hasta que ya muy desmejorada, ajada, con un cigarro en su mano y sin ningún atractivo físico, un calesero negro le dice: Ya tu ni chicha ni limoná. Termina la historieta con la mulata moribunda en una camilla portada por cuatro negros que la conducen al hospital.

En otras historietas seriadas pero de temas monográficos distintos al tratado, existen una serie de marquillas sueltas con un claro matiz erótico, de muy diferente factura y de fábricas distintas, en las que se nos dan pinceladas de la relación erótica entre mulatos/as y blancos/as, o entre personajes de la misma raza y distinto sexo, casi siempre negros. Es el caso de la viñeta de la "Fábrica de E. Guilló" en la que un comerciante a la puerta de su negocio y fumando displicentemente se dirige a una mulata, que se "pavonea" delante de él y que le contesta: Ay D. José no me diga eso. O aquella otra de "La Honradez", que en su serie "cosas de La Habana" tiene una viñeta, en la que una señora sentada en quitrín, y que parece estar sobre las piernas de un varón con sombrero de copa (particularmente creemos puede ser el cochero de color), que muy afanado, a juzgar por la posición, está sometiendo a la dama a ciertas prácticas que podemos imaginar cuando ésta se queja diciendo: Avemaría Pancrasio; me vas machucando 

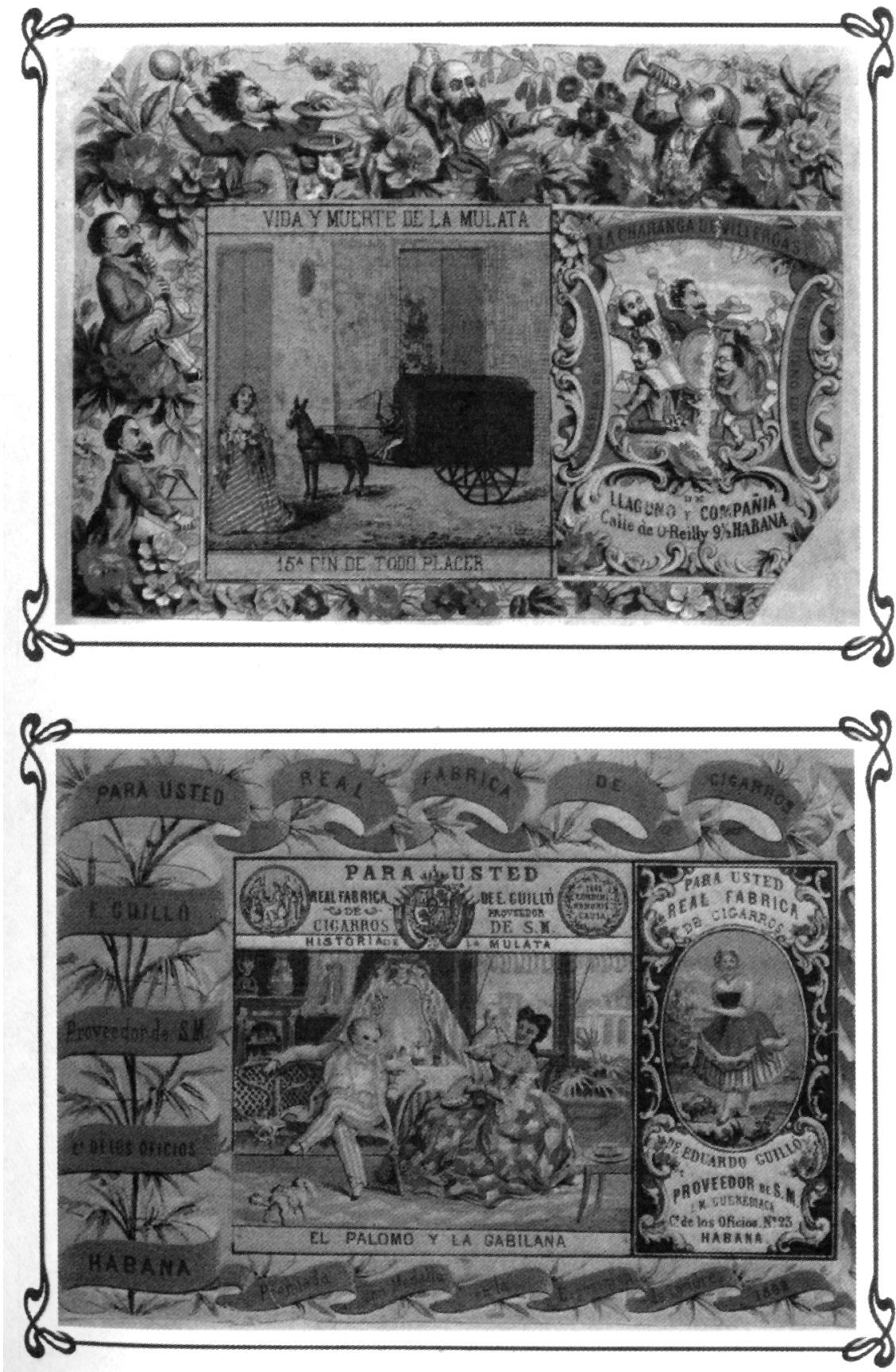
JUAN ANDREO GARCÍA Y ALBERTO JOSÉ GULLÓN ABAO
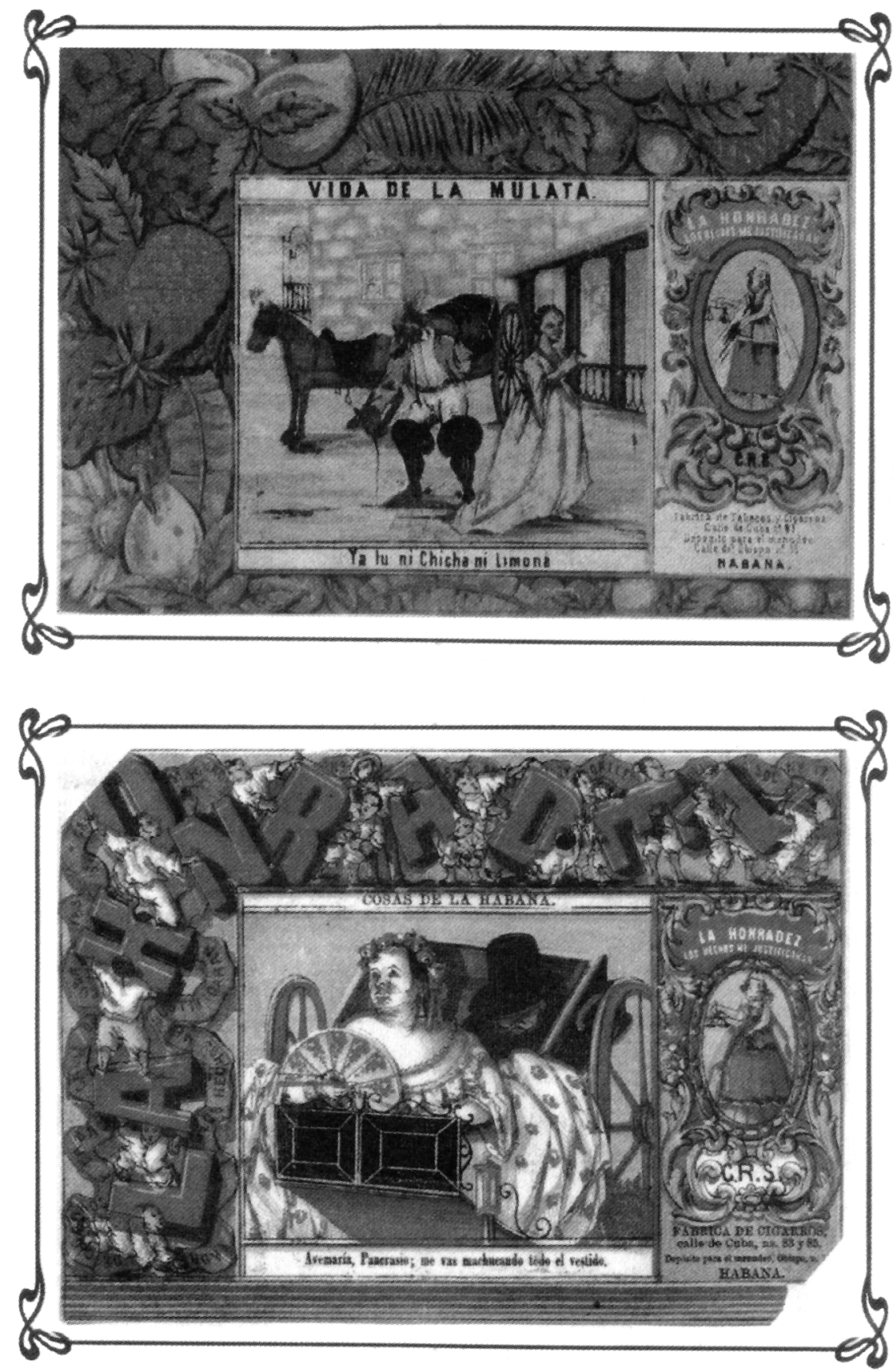

148

Anuario de Estudios Americanos 
todo el vestido. Desde luego el carácter caricaturesco y burlón sobre los usos y costumbres habaneros, se muestra en esta colección de forma estentórea.

Otras marquillas nos ilustran sobre el engaño de las mulatas al hombre blanco. Un claro ejemplo es el que se ilustra en la estampilla de la "Fábrica de Eduardo Guilló" en la que, en un baile de salón — quizás un baile de máscaras - unos caballeros de la alta sociedad colonial (lo deducimos por su atuendo) bailan con mujeres de color que llevan un antifaz y cuyo pie reza: Aquí se vende gato por liebre, haciendo referencia clara al problema de la mulata clara pero con una "raza legal" negra.

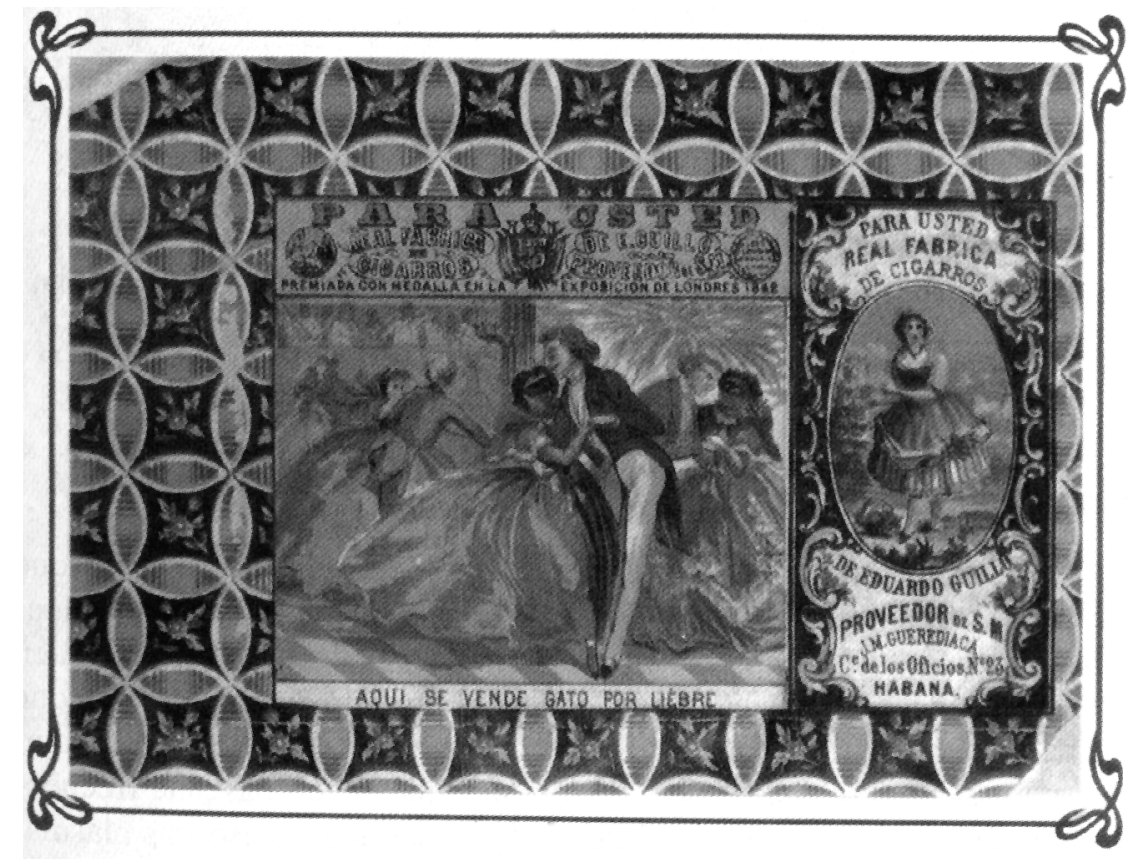

Por último, traemos a colación el caso de aquellas marquillas que sin ninguna ambigüedad en la imagen, pero quizá sí en el texto, manifiestan en toda su gravedad el triste destino a que se ven abocadas estas mujeres: la prostitución. En una marquilla de la "Fábrica E. Guilló", se ve un soldado que sale vistiéndose de la casa de una "semi desnuda" mujer negra que, alargando la mano y con un rictus de tristeza, parece que le está exigiendo el precio de sus "favores": Depué que comite la papa salá. 


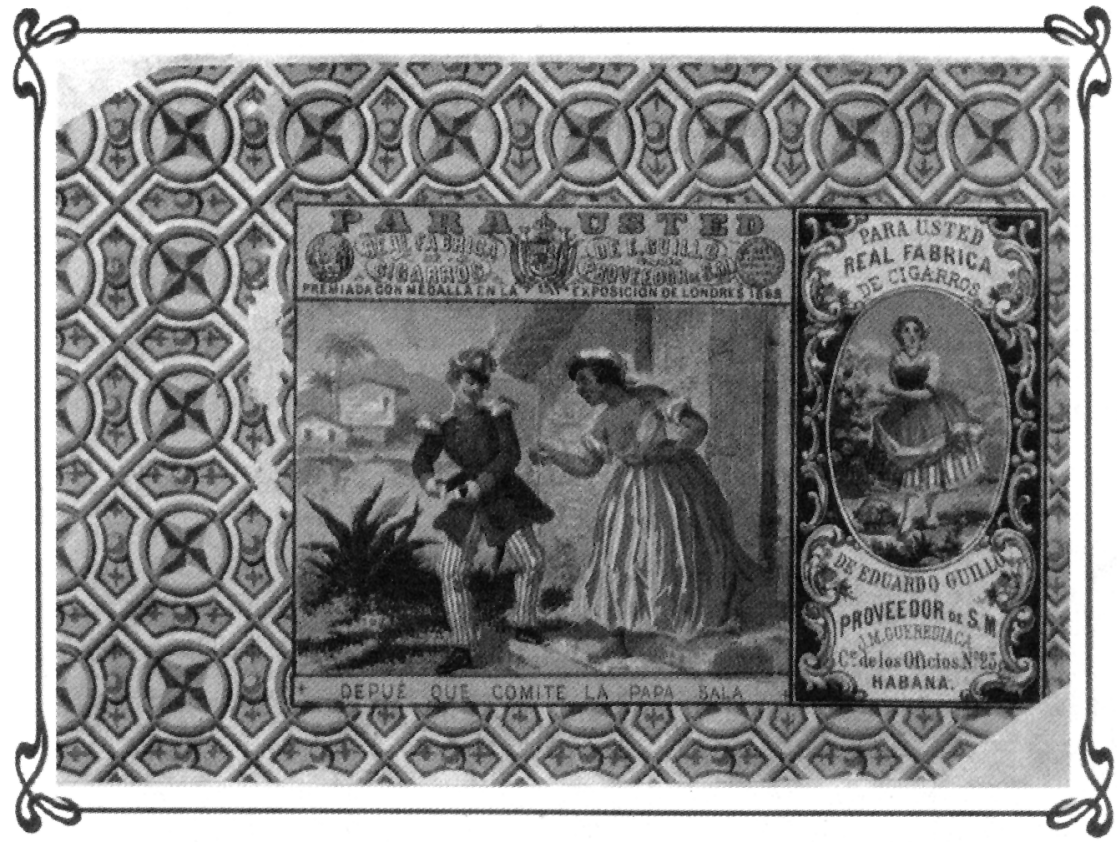

\section{El escenario y los personajes}

Nuestro interés por estos "cromitos" es doble. En primer lugar porque muestran sin tapujos aparentes y con un gran realismo, una truculenta, aunque moralizante historia que, si aparece en ellos, es porque está inserta en la vida cotidiana de la sociedad de Cuba y es el reflejo de un problema que abruma a esa sociedad, o al menos a las autoridades: El de una "prostitución" no reglada o incontrolada, a la que se dedican con bastante frecuencia gran número de mulatas. En segundo lugar porque las escenas plasmadas nos dicen mucho de esa sociedad, nos hablan de las gentes implicadas, nos señalan unos marcos habitables, un entorno social, unos utensilios, unos ambientes íntimos y a veces públicos, etc.

En las diferentes historietas que hemos citado, destacan una serie de factores específicos que merece la pena resaltar porque, a pesar de ser aspectos que generalmente se repiten en todo tiempo y lugar, merecen ser rescatados ya que interesa ver cómo se plasman y concretan en una sociedad como la cubana y en un momento dado, la segunda mitad del siglo XIX. 
Lo primero que apreciamos es el reflejo de una cultura eminentemente urbana. En las "vidas de la mulata" no aparece un ambiente propiamente rural, no aparece la mulata en los ingenios o en la manigua; el escenario es una zona de arrabal, extramuros o cercana al puerto pero siempre en los entornos de la ciudad, donde se inicia el principio de la historia; luego conforme la mulata gana encantos y se hace adulta, el escenario pasa a ser el centro urbano, o por lo menos la parte más cuidada donde viven criollos blancos y penínsulares: jardines, salones de baile, teatros, incluso casas bastante acomodadas y lujosas; para terminar de nuevo en esos escenarios un tanto tenebrosos y arrabaleros de las callejas del extrarradio y en los hospitales de pobres.

Es obvio, que la relación entre los distintos personajes de la historieta queda establecida por los dos ejes de raza y clase; a partir de esas coordenadas podemos estudiar el mundo que rodea la vida de estas mulatas. Nosotros, por mera cuestión de orden, vamos a estructurar los personajes según el sexo.

\section{Personajes femeninos}

La mujer negra esclava o sirvienta manumitida, que vive en las zonas urbanas más deprimidas, cercanas casi siempre al puerto (La Habana), en una choza, responde perfectamente a la descripción que de ella hace una viajera del siglo XIX por la Isla de Cuba:

"La mujer se da poco al público; sólo las negras se pasean por todas las partes con los hombros y el pecho descubiertos, con un cigarro en la boca y echando torrentes de humo; se sientan en las puertas de las casas y juegan con el niño/a blanco que llevan en los brazos". ${ }^{19}$

Esta mujer, a lo largo de la historieta, desarrolla un papel muy parecido al del "ama" de un burdel. Como su relación con el blanco no le sirve mucho en sus aspiraciones y deseos, se da a entender en algunas viñetas que es la "incitadora" o "iniciadora" de su hija para que utilice sus "encantos" a fin de lograr lo que ella no pudo: dinero, comodidad y huida del submundo en el que ha nacido.

19 Merlín, Condesa de: Viaje a La Habana. La Habana, 1974, pág. 207. Es evidente que la Condesa de Merlín no investigó más sobre ese niño/a blanco/a, es muy probable que fuese mulato/a. 
El personaje del ama no aparece de manera clara en las litografías, pero su existencia es evidente. Se trataba, en la mayoría de los casos, de antiguas prostitutas que sacaban licencias de apertura de casas toleradas con el capital que habían ahorrado en su juventud; ellas serán las interlocutoras válidas con la autoridad; "matrona isleña de aspecto hombruno, polisarcica, con voz ronca y en cada mano, ahorcando sus dedos achorizados, ostentaba un verdadero capital de sortijas de gruesos diamantes entre alguna que otra tumbaga". ${ }^{20}$ No sólo controlaban a sus pupilas, sino que también las sancionaban, pues los reglamentos les otorgaban un poder del que resultaba casi imposible escapar. Con todo, opinamos que esta situación varió en el período republicano al controlar los "chulos" - integrados en las redes internacionales de prostitución - las casas de lenocinio, transformándose las amas — que en ocasiones son las favoritas de los souteneuren gestoras de las casas bajo sus dominios. ${ }^{21}$ Las amas eran las responsables y encargadas de controlar cualquier escándalo de la casa; tenían que llevar a las pupilas al Hospital de la higiene; acreditarlas a la hora del registro en el censo de prostitutas; encargarse de que las meretrices estuvieran a las horas dispuestas para el reconocimiento médico; controlar que vistieran con decoro y no llamaran la atención a los hombres desde los balcones o ventanas, así como las entradas y salidas de sus pupilas; informar a la policía de quienes pernoctaban durante tres días en el mismo local; etc.

El reglamento de 1892, confirma muchas de nuestras sospechas acerca del poder leonino que el ama ejercía sobre sus pupilas; ${ }^{22}$ así, a través de las prohibiciones que se establecieron para evitar los abusos de las amas, descubrimos que existía un absoluto control sobre la posibilidad de cambiar de domicilio libremente por parte de las pupilas, reteniéndolas por supuestas deudas de ropas y mobiliario que, en numerosos casos, les había sido vendido directamente por el ama a altos precios. Eran corrientes las injurias y los malos tratos, para establecer un cierto orden y evitar las "fugas"; también se les prohibía salir de las casas y fomentaban el lesbianismo como forma de control entre las pupilas para tratar de evitar el poder indirecto que ejercían los chulos sobre ellas. ${ }^{23}$

20 Céspedes, Benjamín de: La prostitución..., pág. 147.

21 Biblioteca Nacional José Martí. La Habana. El Heraldo. La Habana, 27 de noviembre de 1923. La policía pugna por descubrir a los jefes de una oficina afiliada a la tenebrosa ASS de la trata de blancas.

22 Reglamento de 1892. C. IV, art. 29.

23 Céspedes: La prostitución..., pág. 204. 
Fue frecuente que los celadores de Higiene, entendiéndose con las amas de casa, alterasen fraudulentamente las órdenes de los inspectores médicos a cambio de dinero o favores sexuales de las pupilas. Las bajas por enfermedad se archivaban en la sección de Higiene por la influencia de las "amas generosas y espléndidas en el arte del soborno", ${ }^{24}$ y se llegó a culpar a los celadores, en 1878 , de la ingente subida de prostitutas no reguladas "quizás por obedecer a la antigua máxima que el silencio es de oro".

Capel describe a otras mujeres mayores, casi siempre españolas, que pululaban en torno a ese oficio y que eran las llamadas alcahuetas, destinadas a captar la atención de jóvenes entre 13 y 16 años que andaban por las calles y a las que se les ofrecía alojamiento inmediato en casas, pensiones y residencias que eran prostíbulos o lugares de trata encubiertos.

Por último, el tercer personaje femenino de nuestra historia, es el sujeto de nuestro estudio: la mulata. Esta mujer es el centro de lo que llevamos dicho y lo que diremos a lo largo de este trabajo. Por eso no nos detenemos en ella en esta enumeración.

\section{Personajes masculinos}

El hombre blanco, casi siempre comerciante o marinero, es el primero que aparece en relación con la mujer negra. En viñetas posteriores se muestra como el fruto de esa relación, la mulata, se ve acosada y cortejada por varones de una clase social más acomodada: criollos o peninsulares hijos de hacendados, los hacendados mismos o personas acaudaladas con un nivel de vida superior al del simple comerciante. Finalmente, la mulata vuelve a sus orígenes (de donde no debía haber salido), a relacionarse con gentes de su propia raza, negros o mulatos.

También están los proxenetas que usan anuncios en los periódicos o se valen de agentes teatrales, agencias de colocación y dueños de restaurantes para captar a las jóvenes bajo falsas promesas. En el caso cubano encontramos a algunos jóvenes mancebos que aspiran a hacerse con el capital que supone el ahorro de las prostitutas, para establecer pequeños negocios. Y cómo no, los chulos que, tras fingir amores apasionados con ellas, obtienen los pocos beneficios de su trabajo, tratándolas en numerosos casos con extrema dureza, cuando no les dan lo que ellos creen que han obtenido.

24 BN, Mss. 20138. La Habana, 5 de octubre de 1867. El gobernador político al comisario del primer distrito sobre el poco efecto que producen las multas. 
Junto a ellos, toda una pléyade de comerciantes o dueños de los inmuebles, que se aprovechan de las meretrices cobrándoles precios abusivos por los productos o las residencias que usan para trabajar, sin las más mínimas condiciones de habitabilidad..$^{25}$

\section{A modo de conclusiones: ¿Qué se refleja en las litografías?}

A la luz de la conjunción de los datos ofrecidos por estas fuentes gráficas y de los que ya poseemos - obtenidos de otras más convencionalespodemos establecer una serie de reflexiones y conclusiones que, si no son originales, sí intentan una aproximación al entendimiento del problema de la prostitución en Cuba que, como decimos, presenta caracteres específicos provenientes de su relación íntima con el "mito sexual" de la mulata.

Casi siempre son los mismos factores los que conducen a la mujer al ejercicio de la prostitución. Ahora bien, en el caso cubano observamos una variante con respecto a otros paises: la presencia de la mulata o la negra a la que, además, se desprecia o se la considera en un escalón social bajísimo como fruto de un racismo implícito y explícito. Los sectores más racistas de la isla sostienen que los cruzamientos étnicos producen una clara degradación de la raza, apoyados en criterios médicos y antropológicos. ${ }^{26}$ Esto genera entre determinados sectores de la población la creencia en la propensión de las mulatas a caer en la prostitución por estar entre dos mundos: "el blanco, al que aspiran llegar y el negro del que son y al que la sociedad que les rodea les hace detestar". Ello facilita que, al ser abandonadas por el hombre blanco, pasen a engrosar las listas de meretrices.

Es evidente que estos discursos sobre la inferioridad genética de la raza de color, según Verena Stolcke, enmascaran las raices socio-económicas y políticas de la desigualdad social. ${ }^{27}$

Si tenemos que hablar de causas de la prostitución de la mujer negra y de la mulata, la más esgrimida por los autores para la entrada en ese mundo de las negras y mulatas es el concubinato. Los datos que tenemos para

25 Ibídem. La Habana, 15 de diciembre de 1862. El gobernador político, sobre informe del comisario del tercer distrito.

26 García González, Armando: "En torno a la antropología y el racismo en Cuba en el siglo XIX", en Cuba la perla de las Antillas. Madrid, 1994.

27 Stolcke: Racismo y sexualidad.., pág. 18. 
1899 nos informan que en la provincia de La Habana existían unas 9.605 parejas de color amancebadas mientras que blancas eran unas 3.881, lo que indica que, cuando menos, era una práctica muy extendida en la isla y, desde luego, no exclusiva de una raza o color. Sin embargo las representaciones gráficas de la época, como hemos visto, reflejan el predominio de la raza negra.

En segundo lugar, esta "evidencia" de la inferioridad genética de la raza negra se une a la percepción secular y machista, del papel tutelar del varón sobre la mujer. En buena medida, el destino de la mujer era someterse a la salvaguarda de una serie de valores que se le inculcaban claramente en la educación que recibía, tanto en la familia como en la escuela. ${ }^{28}$ Ello sin contar con que el número de mujeres escolarizadas debía ser reducido y que existía un alto nivel de analfabetismo generalizado entre los grupos más desfavorecidos, que afectaría sobre todo a las mujeres y especialmente a las de color. Incluso se llega a dudar en algunos informes, de claro matiz racista, sobre si las mujeres de color tenían capacidad: “...esos cerebros tan imbuidos de supersticiones de todos géneros (de que) pudieran brotar alguna idea civilizadora".

Por último tenemos el hecho de que los trabajos que tradicionalmente desarrollaban mulatas y negras, sobre todo en el servicio doméstico, justificaba que pronto entraran en relación con el hombre blanco.

La sociedad cubana acepta sin ambages la "historia de la mulata", incluso no la oculta; plasma, dejando abiertas numerosas posibilidades de interpretación (moralizante, ejemplarizante, simplemente irónica o por puro afán pornográfico), la dedicación a una profesión o a una forma de vida a la que, de manera inequívoca, había un sector de la sociedad que estaba abocado. Este hecho se puede comprobar perfectamente a través de la opinión de la Sociedad Económica de Cuba:

"El cresido número de estas (niñas pardas y morenas) y de cuyo abandono en sus primeros años, viene la mayor parte de las desdichas, que nos rodean. Su pobresa, y ociosidad continua quando han llegado a ser mugeres, y el poco, o ningún honor, que su mismo nacimiento les inspira, son la causa de que muchos hombres, de todas clases. falten a sus deveres los mas sagrados, que la juventud se desrregle demaciado

28 Rodríguez Rodríguez, Aurea Verónica: "Bosquejo histórico de la enseñanza primaria en la Isla de Cuba: 1790-1868”. Arbor, n. ${ }^{\circ}$ 567. Tomo CXLIV. Madrid, 1993. Provencio Garrigos, Lucía: "Un claroscuro ilustrado: mujer y educación en la Cuba de principios del siglo XIX". En Actas del Congreso Internacional de Historia de la Familia. Una nueva perspectiva sobre la sociedad Europea. Murcia, 1994. En prensa. 
temprano (...) y quando el lustre de los pocos años falta, a causas de sus propios desarreglos o de una edad mas adelantada, les queda el recurso de ser terceras de otras que empiesan...". ${ }^{29}$

Estas palabras, escritas en 1788, vienen a confirmar el mito de la mulata como supremo objeto sexual. Y concuerdan con la autorizada opinión de Moreno Fraginals:

"La mulata es idealizada muy pronto y hasta hoy, como el supremo ideal del animal sexual. Su educación como cebo de hombres y la utilización del sexo como vía de mejoramiento social y económico, generan la existencia de uniones más o menos permanentes, no legitimadas. La mulata era con quien el señorito "estrenaba" su vida sexual. A ellas no se les exigía amor, ni siquiera fidelidad. Ella, despreciada como raza, pero apetecida como leyenda sexual, perfeccionó sus dotes femeninas e hizo profesión perfecta del sexo, como catapulta para erguirse sobre la miseria y el desprecio". ${ }^{30}$

La mulata es esa mujer que, por el color de su piel, aspira a desclasarse, o mejor, salir de la oscuridad profunda a que la sociedad esclavista y racista ha sometido a las gentes de color; su tez clara es la ocasión para abandonar ese estrecho túnel; sus armas son su cuerpo y su belleza y su oficio la prostitución, más o menos encubierta, pero prostitución al fin.

Parece que, indefectiblemente, la vida de la mulata estaba destinada a desempeñar el papel al que la sociedad la sometía. Veamos el pasaje narrado por Walter Goodman en su estancia en Cuba, en el que una mulata clara, Herminia, le confiesa sus cuitas. Herminia pregunta a Tunicú sobre qué hacer de la proposición al matrimonio de un negro y Tunicú le contesta:

"Eres demasiado bella y refinada para el hijo de un negro. Cuando te cases, Herminia mia, debes de hacerlo con alguien que tenga mejores antecedentes". Herminia le pregunta: “Crees posible que yo alguna vez me case tan bien como tú deseas?”; sin mirarla, como ocultando lo que piensa, le contesta "¿Por qué no va a casarse bien mi Herminia? Si ella es joven, bella, bien educada", Herminia, siguiendo la escena y como hablando de una tercera persona, contesta entre sollozos: "i...e hija de una esclava!". ${ }^{31}$

29 Archivo General de Indias, Santo Domingo, 1476-B. Estracto de las juntas celebradas por la Sociedad Económica de Cuba en el año de 1788. Agradecemos a la licenciada Provencio Garrigós el habernos permitido la utilización de alguna de la documentación que está consultando para la confección de su tesis doctoral sobre educación y mujer en la Cuba del Siglo XIX, en concreto nos ha pasado fotocopia del documento que acabamos de citar.

30 Moreno Fraginals: Cuba / España..., pág. 186.

31 Goodman, Walter: Un Artista en Cuba. La Habana, 1965, págs. 274-275. 
Desde luego opinamos con Jean Lamore que el mito de la mulata (mujer fácil y mujer de perdición) no es más que una máscara que esconde la realidad de una sociedad que coarta y determina un papel muy concreto por miedo a perder sus privilegios. O lo que Verena Stolcke llama miedo a la "africanización de Cuba". ${ }^{32}$

Eso es precisamente lo que se ve en las marquillas. Ellas inconscientemente, creemos, reflejan una situación de facto asumida por la sociedad que las dio a luz y que, además, opinaba en palabras de un coetáneo lo siguiente:

"sin estímulos eficaces para ser honrada, sin el freno de la opinión, que la condena inexorablememnte antes de haber delinquido, su horóscopo la lleva forzosamente a la inmoralidad. La mulata se casa en nuestros paises en raras ocasiones, pues no varía su destino con el matrimonio. Su condición, como esposa legítima del mulato, es la misma que de torpe manceba. $\mathrm{Ni}$ de un modo ni de otro sale de la inferioridad y abyección a que nuestras preocupaciones la reducen. Ingenua, libertina, o sierva, sucumbe facilmente a las primeras insinuaciones aduladoras que le dirigen.....ya en las "cunas" de Guanabacoa, ya en los salones del Louvre, y sucumbe sucesivamente a dos, a tres, y a más, interin no se marchiten sus atractivos...Nunca frisa en los diez y seis abriles sin rendirse...lo común es que...sumida en el lodo inmundo de la concupiscencia, la entierren pobre y joven a los ocho dias de haber bailado una noche entera". ${ }^{33}$

32 Stolcke: Racismo y sexualidad..., pág. 60

33 Ezponceda, Eduardo: La mulata, estudio filológico, social y jurídico. Madrid, 1878. Citado por Jean Lamore. ed.: "Introducción" a la obra de Cirilo Villaverde: Cecilia Valdés o la loma del Angel. Madrid, 1992, pág. 44. El presente artículo debe mucho, precisamente al profesor Lamore, a la luz de largas conversaciones en lugares como Santiago de Cuba, Leipzig o Cartagena de Levante, y por supuesto trás la lectura de algunas de sus obras, hemos empezado a comprender, siquiera un poco, el fascinante mundo de esa sociedad mestiza que ha dado un fenómeno tan extraordinario como el de la mulatez. 